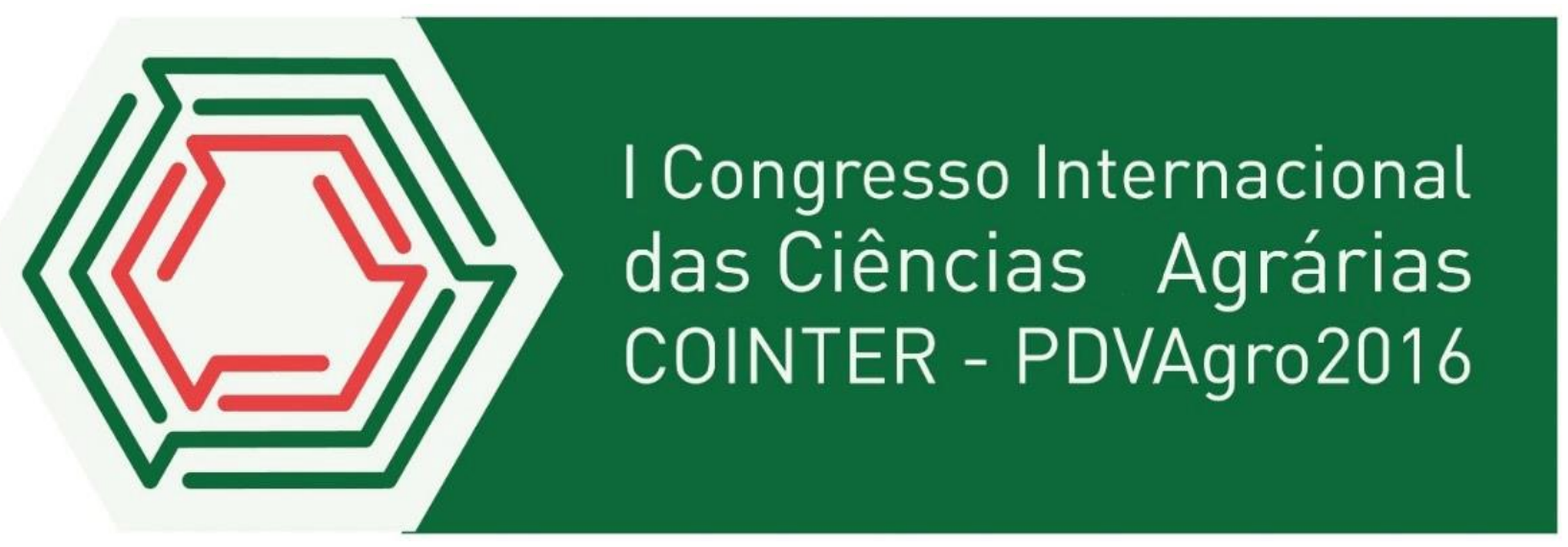

\title{
DIAGNÓSTICO E PERFIL DOS PRODUTORES RURAIS DA FEIRA AGROECOLÓGICA DO MUNICÍPIO DE BANANEIRAS - PB
}

\author{
Apresentação: Pôster
}

Fábio Fernandes de Araújo ${ }^{1}$; Wellignton Farias dos Santos²; José Osmar Souza Dantas³; Welliton Barros de Magalhães ${ }^{4}$; Raunira Pereira da Costa ${ }^{5}$

\section{Introdução}

Parece haver consenso entre os especialistas de que o modelo produtivista de agricultura derivado da Revolução Verde está em crise e que é necessário mudar a forma de se produzir e de se relacionar com o meio ambiente (HESPANHOL, 2008).

Dentre as implicações produzidas pela difusão do pacote da Revolução Verde, Siqueira et al. (2010) destacam a dependência de insumos industrializados, o aumento dos custos de produção, o êxodo rural, a utilização de maquinário agrícola e a exclusão da agricultura familiar. Consequências estas, que podem vir associadas aos problemas ambientais como a erosão dos solos, a perda da biodiversidade, a crescente contaminação dos recursos hídricos, dos alimentos, dos animais e do homem, entre outros.

No município de Bananeiras - PB, a produção orgânica é uma atividade de caráter bastante significativo no que se refere ao desenvolvimento econômico e, principalmente, a inserção social de diversas famílias residentes em terras agricultáveis na zona rural do município. Como estratégia de incentivo ao consumo desses produtos, a governo municipal desenvolve semanalmente a feira

\footnotetext{
${ }^{1}$ Mestrando em tecnologia Agroalimentar, UFPB, fabio.fernandesn18@gmail.com

${ }^{2}$ Mestrando em tecnologia Agroalimentar, UFPB, welligtonfs@outlook.com

${ }^{3}$ Mestrando em tecnologia Agroalimentar, UFPB, osmar.dantas@gmail.com

${ }^{4}$ Engenheiro agrônomo, UFPB/CCHSA, welliton.barros@ufv.br

${ }^{5}$ Docente do Departamento de Gestão e Tecnologia Agroindustrial, UFPB/CCHSA, arinuar@hotmail.com
} 
agroecológica, concomitante a realização da feira convencional. Com o espaço da feira os agricultores familiares têm a oportunidade de comercializar e divulgar sua produção.

O objetivo deste trabalho foi analisar o perfil dos produtores rurais da feira agroecológica do município de Bananeiras-PB com enfoque na adoção de práticas agroecológicas.

\section{Fundamentação Teórica}

Considerando a crescente demanda por produtos orgânicos proporcionados pelas exigências dos mercados interno e externo, os anseios da sociedade em obter produtos naturais, a necessidade de preservação do meio ambiente e de dar garantia de vida às futuras gerações, percebe-se que o mercado de produtos orgânicos, de um modo geral, é bastante expressivo e apresenta-se como uma proposta duradoura e auto sustentável, privilegiando a qualidade de vida dos produtores, consumidores e a preservação ambiental (EMBRAPA, 2007). Diante desta realidade, o mercado de produtos de origem orgânica vem ganhando cada vez mais espaço. É o caso das tradicionais lojas de produtos naturais e feiras orgânicas (ARAÚJO; PAIVA, 2007).

Segundo Marques et. al. (2010) especialmente nas cidades grandes a comercialização de produtos orgânicos tem crescido, mas por outro lado o mesmo não acontece com a mesma intensidade nas cidades de menor porte. Esta realidade pode ser atribuída à falta de divulgação, principalmente em cidades pequenas como afirma Mesquita (2006) ao dizer que um fato interessante, é que não existe propaganda em veículos de comunicação como rádio, televisão, e sim somente o tradicional "boca-a boca". Este aspecto Pode limitar o consumo de produtos agroecológicos nas feiras, tendo em vista que o sucesso destas em grande parte deve-se ao nível de conhecimento e informações detido pelo consumidor com relação ao produto orgânico. Vásquez et. al (2008) enfatizam também a necessidade de divulgação dos benefícios que o consumo dos produtos derivados da agricultura orgânica proporciona à saúde pessoal, da família e para o desenvolvimento sustentável.

\section{Metodologia}

O trabalho foi conduzido no município de Bananeiras - PB que se encontra inserido na Mesorregião Agreste Paraibano e Microrregião do Brejo Paraibano, com as coordenadas 


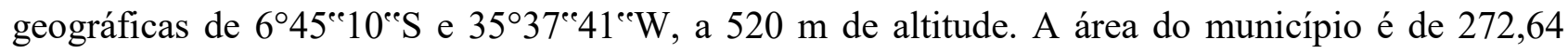
km2 e corresponde a 22,8\% da superfície do Brejo Paraibano (GONDIM, 1999).

A cidade de Bananeiras-PB possui uma feira agroecológica que comercializa somente produtos orgânicos. A partir desse perfil delimitou-se esta feira para a realização de um diagnóstico sobre os produtores e/ou feirantes de produtos orgânicos.

Os dados foram obtidos através da aplicação de um questionário semiestruturado, do qual foram extraídas informações como o perfil do feirante, em caso de produtor o perfil da propriedade, como esses produtores se organizam, como se comportam em relação a questões ambientais, gênero, tempo de sindicalização, estrutura fundiária (número e tamanho), produção principal, práticas agrícolas adotadas, entre outras.

A pesquisa foi realizada em apenas um dia, e aconteceu no mês de agosto de 2015. Apesar de extenso, o questionário abordava questões simples, de tal forma que não dificultava ou atrapalhava o feirante. Assim foi possível entrevistar os feirantes ao mesmo tempo em que eles estavam trabalhando.

Os dados foram organizados numa planilha eletrônica construída no Microsoft Office Excel®, versão 2010 e, em seguida gerou-se um quadro visando facilitar as análises de distribuição de frequência das variáveis.

\section{Resultados e Discussões}

Em relação aos aspectos socioeconômicos dos entrevistados, na delimitação quanto ao perfil, no que diz respeito à relação de gênero, predomina o sexo masculino entre os entrevistados perfazendo $67 \%$ da amostra e o feminino 33\%, fato que demonstra que a agricultura é ainda uma profissão na qual o número de homens na atividade é predominante, coincidindo com os estimativos disponibilizados pelo Ministério do Trabalho (FERRARI, 2004).

Na observação que se fez com relação à faixa etária pode-se verificar que 33\% estavam na faixa de 25 a 35 anos, 50\% deles tem de 36 a 45 anos e, finalmente, 16\% dos agricultores entrevistados possuem entre 46 a 60 anos. Desse modo, observa-se que a maioria dos agricultores encontra-se inserida na classe adultos-jovens (Quadro 1). 
Com relação à escolaridade, 50\% estudaram apenas o ensino fundamental incompleto e 50\% corresponde aqueles sem nenhuma instrução (Quadro 1). Esses dados revelam que a população entrevistada possuía um nível precário de escolaridade, demonstrando um decréscimo na escolarização da população adulta jovem, que foi a maioria dos entrevistados.

No que diz respeito a produzir de forma agroecológica, 83, \% responderam que produzem dessa forma devido a um menor custo de produção e a venda direta dos produtos, 67\% estão relacionados com o melhor preço e com a preservação do meio ambiente (Quadro 1). Apesar de ser dita como uma atividade lucrativa, por alguns daqueles que a praticam, a agricultura familiar e seus adeptos ainda enfrentam problemas vindos desde o Brasil colônia. Problemas tais como políticas públicas que atendam realmente às necessidades socioeconômicas e culturais destes agricultores, concentração fundiária, além dos problemas internos, como: falta de mão de obra qualificada, ausência de insumos externos, como máquinas e assistência técnica são problemas que compõem a realidade do campo brasileiro.

Todos os produtores são assentados $(100 \%)$, sendo que a maioria os próprios donos da terra (83\%). Com relação à situação da feira, $100 \%$ são produtores/vendedores de seus próprios produtos, evitando assim a interferência dos intermediários. Observa-se o interesse dos produtores em participarem de sindicatos e associações, onde $100 \%$ responderam participarem de pelo menos um dos dois (Quadro 1).

Quando 1: Perfil social dos produtores rurais da feira agroecológica de Bananeiras-PB

\begin{tabular}{|l|c|}
\hline VARIÁ VEIS & $\%$ \\
\hline Gênero & 67 \\
\hline Masculino & 33 \\
\hline Feminino & 33 \\
\hline Idade & 50 \\
\hline $25-35$ & 16 \\
\hline $36-45$ & \\
\hline $46-60$ & 16 \\
\hline $\mathbf{N}^{0}$ de pessoas na propriedade & 16 \\
\hline 05 pessoas & 67 \\
\hline 06 pessoas & \\
\hline Mais de 06 pessoas & 50 \\
\hline Escolaridade & 50 \\
\hline Sem instrução & \\
\hline Fundamental Incompleto & 0 \\
\hline Situação da Propriedade & 100 \\
\hline Proprietário & \\
\hline Assentado & 100 \\
\hline Participa de sindicato ou associação & \\
\hline Sim & \\
\hline
\end{tabular}




\begin{tabular}{|l|c|}
\hline Não & 0 \\
\hline Situação quanto às feiras & 0 \\
\hline Apenas produtor & 0 \\
\hline Apenas vendedor & 100 \\
\hline Produtor/Vendedor & 22,33 \\
\hline Porque produz de forma agroecológica & 27,66 \\
\hline Melhor preço & 22,33 \\
\hline Venda direta & 27,66 \\
\hline Preservação ambiental & 100 \\
\hline Menor custo & \\
\hline TOTAL & \\
\hline
\end{tabular}

O quadro 1 apresenta a composição da renda que os feirantes no Município de Pombal - PB conseguem tirar na feira, onde mais da metade (55\%) conseguem tirar de 1 a 2 salários mínimos por mês, já o restante (45\%) conseguem até um salário mínimo. Entretanto, foi observado que a maioria sobrevive com apenas a receita das vendas nas feiras, este número atingem uma média de $67 \%$ dos feirantes que não tem renda fixa, o que deixa evidente que está sendo uma vantagem para entrevistados, comercializar na feira agroecológica de Bananeiras-PB. Silva et al. (2007) analisando a comercialização de produtos agrícolas orgânicos como fator de inclusão social e econômica, revela que 5\% dos participantes do assentamento Chico Mendes, possuíam algum tipo de renda extra-trabalho, principalmente oriunda de aposentadorias.

\section{Conclusões}

A feira livre ecológica mostra ser um eficiente canal de comercialização e instrumento muito útil na viabilização dos pequenos agricultores familiares. A maioria dos feirantes possui baixa escolaridade, apenas o primeiro grau incompleto, ou mesmo sem nenhuma instrução de ensino.

A feira agroecológica do município de Bananeiras-PB apresenta-se como uma oportunidade de geração de renda para as famílias envolvidas, especialmente pelo fato de a população ser em sua maioria oriunda de áreas rurais. No entanto, é fundamental que sejam criadas políticas que apoiem e garantam a comercialização dos produtos na região para fortalecerem a atividade.

\section{Referências}

EMBRAPA. Perfil do consumidor e do consumo de produtos orgânicos no Rio Grande do Norte, 2007. Disponível em: <www.cpatc.embrapa.br/publicacoes_2007/doc-125.pdf>. Acessado em 13/09/2016. 
HESPANHOL, R. A. de M. Perspectivas da agricultura sustentável no Brasil. Confins, n. 2, p.1-13, 2008.

MARQUES, M. A. N. et. al. Comercialização e aceitação de produtos orgânicos em duas redes de supermercado no município de Mossoró - RN. 2010. 62 $2^{\mathrm{a}}$ Reunião Anual da SBPC. Disponível em: http://www.sbpcnet.org.br/livro/62ra/resumos/resumos/329.htm. Acesso: 28/09/2016.

MESQUITA, Z. Agricultores e consumidores de produtos orgânicos: uma aproxima- ção necessária. Resumos do I Congresso Brasileiro de Agroecologia, Rev. Bras. de Agroecologia. Vol.1 No 1/nov. 2006.

SILVA, A. M. N; ALBUQUERQUE, J. L.; FILHO, D. S.; SILVA, E. S.; NASCIMENTO, R. P. L. 2007. Comercialização de Produtos Agrícolas Orgânicos como Fator de Inclusão Social e Econômica. Disponível em http://www.sober.org.br/palestra/9/946.pdf. Acesso em: 05 set. 2016.

SIQUEIRA, H. M de.; SOUZA, P. M de.; RABELLO, L. K. C.; FERREIRA, R de S.; ALVAREZ, C. R da S. Transição agroecológica e sustentabilidade dos agricultores familiares do território do Caparaó-ES. Revista Brasileira de Agroecologia. v.5, n.2, p. 247-263, 2010.

VÁSQUEZ, S. F. et. al. Agricultura Orgânica: Caracterização do seu consumidor em Cajazeiras- 